\title{
Impact of obesity on complications and outcomes: a comparison of fusion and nonfusion lumbar spine surgery
}

\author{
Ikemefuna Onyekwelu, MD, ${ }^{1}$ Steven D. Glassman, MD, ${ }^{1,2}$ Anthony L. Asher, MD, ${ }^{3}$ \\ Christopher I. Shaffrey, MD, ${ }^{4}$ Praveen V. Mummaneni, MD, ${ }^{5}$ and Leah Y. Carreon, MD, MSc ${ }^{2}$
}

\begin{abstract}
${ }^{1}$ Department of Orthopaedic Surgery, University of Louisville School of Medicine; ${ }^{2}$ Norton Leatherman Spine Center, Louisville, Kentucky; ${ }^{3}$ Carolina Neurosurgery \& Spine, Charlotte, North Carolina; ${ }^{4}$ Department of Neurosurgery, University of Virginia, Charlottesville, Virginia; and ${ }^{5}$ Department of Neurological Surgery, University of California, San Francisco, California
\end{abstract}

\begin{abstract}
OBJECTIVE Prior studies have shown obesity to be associated with higher complication rates but equivalent clinical outcomes following lumbar spine surgery. These findings have been reproducible across lumbar spine surgery in general and for lumbar fusion specifically. Nevertheless, surgeons seem inclined to limit the extent of surgery, perhaps opting for decompression alone rather than decompression plus fusion, in obese patients. The purpose of this study was to ascertain any difference in clinical improvement or complication rates between obese and nonobese patients following decompression alone compared with decompression plus fusion for lumbar spinal stenosis (LSS).

METHODS The Quality Outcomes Database (QOD), formerly known as the National Neurosurgery Quality and Outcomes Database ( $\left.N^{2} Q O D\right)$, was queried for patients who had undergone decompression plus fusion (D+F group) versus decompression alone ( +0 group) for LSS and were stratified by a body mass index (BMI) $\geq 30 \mathrm{~kg} / \mathrm{m}^{2}$ (obese) or $<30$ $\mathrm{kg} / \mathrm{m}^{2}$ (nonobese). Demographic, surgical, and health-related quality of life data were compared.

RESULTS In the nonobese cohort, 947 patients underwent decompression alone and 319 underwent decompression plus fusion. In the obese cohort, 844 patients had decompression alone and 337 had decompression plus fusion. There were no significant differences in the Oswestry Disability Index score or in leg pain improvement at 12 months when comparing decompression with fusion to decompression without fusion in either obese or nonobese cohorts. However, absolute improvement in back pain was less in the obese group when decompression alone had been performed. Blood loss and operative time were lowest in the nonobese D+0 cohort and were higher in obese patients with or without fusion. Obese patients had a longer hospital stay (4.1 days) than the nonobese patients ( 3.3 days) when fusion had been performed. In-hospital stay was similar in both obese and nonobese D+0 cohorts. No significant differences were seen in 30-day readmission rates among the 4 cohorts.
\end{abstract}

CONCLUSIONS Consistent with the prior literature, equivalent clinical outcomes were found among obese and nonobese patients treated for LSS. In addition, no difference in clinical outcomes as related to the extent of the surgical procedure was observed between obese and nonobese patients. Within the D+0 group, the nonobese patients had slightly better back pain scores at 2 years postoperatively. There may be a higher blood product requirement in obese patients following spine surgery, as well as an extended hospital stay, when fusion is performed. While obesity may influence the decision for or against surgery, the data suggest that obesity should not necessarily alter the appropriate procedure for well-selected surgical candidates.

https://thejns.org/doi/abs/10.3171/2016.7.SPINE16448

KEY WORDS obesity; lumbar spinal stenosis; lumbar fusion; lumbar decompression; clinical outcomes

$\mathrm{S}$ OCIETY is facing an obesity epidemic. Since 2003, more than one-third of the US adult population exceeds the World Health Organization's definition of obesity (body mass index $[\mathrm{BMI}] \geq 30 \mathrm{~kg} / \mathrm{m}^{2}$ ).${ }^{19}$ Certainly, this will have a large impact on health care as a whole and on musculoskeletal disorders especially, including degenerative conditions of the spine such as stenosis, mechanical disc collapse, and spondylolisthesis. In addition to the growth of the aging population, spine surgeons will now be faced with an increasing number of obese patients

ABBREVIATIONS BMI = body mass index; $\mathrm{D}+\mathrm{F}=$ decompression plus fusion; $\mathrm{D}+0$ = decompression alone; $\mathrm{LSS}=$ lumbar spinal stenosis; ODI = Oswestry Disability Index; $\mathrm{PRO}=$ patient-reported outcome; $\mathrm{QOD}=$ Quality Outcomes Database; $\mathrm{SSI}=$ surgical site infection .

SUBMITTED April 20, 2016. ACCEPTED July 22, 2016.

INCLUDE WHEN CITING Published online October 14, 2016; DOI: 10.3171/2016.7.SPINE16448. 
who require operative care. Historically, obesity has been associated with a higher incidence of degenerative musculoskeletal disorders and may generate a higher risk for complications after surgery. $12,25,26,31$

Systematic reviews have identified obesity as an independent risk factor for increased blood loss, prolonged operating time, and more frequent complications with lumbar fusion surgery. ${ }^{1,10,14}$ While most studies have revealed either a higher complication rate or increased resource utilization, inferior clinical outcomes in obese patients have not been consistently demonstrated. ${ }^{14,28}$ Despite the current lack of evidence, a tendency to favor less extensive, nonfusion procedures in obese patients is plausible given the historically higher postoperative complication rates associated with these patients. One possible reason for these higher rates could be that patients with higher BMIs are at risk for longer and more technically difficult procedures..$^{10,12,25,26,31}$ Decompression alone involves less time on the operating table and thus may be a preferred treatment strategy to lower risks.

Given the previous literature reporting satisfactory outcomes with lumbar fusion in obese patients, $5,14,15,22,25,29$ we hypothesized that obese and nonobese patients would have comparable clinical benefit following lumbar spine surgery regardless of whether lumbar fusion was part of the procedure. Therefore, the purpose of the current study was to compare the outcomes of obese versus nonobese patients who had undergone surgical treatment for the diagnosis of lumbar spinal stenosis (LSS). In particular, we hoped to ascertain any differences in outcomes and complication rates when comparing decompression alone to decompression plus fusion procedures.

\section{Methods}

From the Quality Outcomes Database (QOD), formerly known as the National Neurosurgery Quality and Outcomes Database ( $\left.{ }^{2} \mathrm{QOD}\right),{ }^{2,17}$ we collected de-identified data on all patients enrolled with a diagnosis of LSS who had complete preoperative, operative, and 1-year postoperative data. The QOD is a prospective observational registry that records 30-day morbidity and preoperative, 3-month postoperative, and 12-month postoperative quality and patient-reported outcomes (PROs) data. Detailed methods of its inception and implementation have been published elsewhere..$^{2,8}$ Collected variables included age at surgery, sex, height, weight, employment status, back and leg pain scores (0-10), ${ }^{16}$ Oswestry Disability Index (ODI) ${ }^{7,8}$ scores, and EQ-5D 6 scores. Surgical variables included American Society of Anesthesiology (ASA) Physical Status classification, surgical approach, laminectomy levels, number of fusion levels, estimated blood loss, and operative time. Thirty-day postoperative readmission, revision surgery, and complications data were also collected. Three- and 12-month back and leg pain scores, ODI scores, and EQ$5 \mathrm{D}$ scores were also obtained.

Obesity was defined as a BMI $\geq 30 \mathrm{~kg} / \mathrm{m}^{2}$. Initial analyses were based on 2 cohorts: obese (BMI $\geq 30 \mathrm{~kg}$ / $\left.\mathrm{m}^{2}\right)$ and nonobese $\left(\mathrm{BMI}<30 \mathrm{~kg} / \mathrm{m}^{2}\right)$. These groups were subdivided into decompression plus fusion $(\mathrm{D}+\mathrm{F})$ and decompression alone (D+0) cohorts. Variables on obese and nonobese patients within each of the surgical subgroups were compared with respect to demographic and surgical parameters, clinical outcomes, and readmission rates at 3 and 12 months.

A subanalysis was performed to determine a dose-dependent effect of BMI on clinical outcomes and readmission rates, and BMI was stratified into nonobese (BMI < $30 \mathrm{~kg} / \mathrm{m}^{2}$ ), obese (BMI $30 \mathrm{~kg} / \mathrm{m}^{2}$ to $<40 \mathrm{~kg} / \mathrm{m}^{2}$ ), and morbidly obese $\left(\mathrm{BMI} \geq 40 \mathrm{~kg} / \mathrm{m}^{2}\right)$.

One-way ANOVA was used to determine any significant differences between continuous variables, and a Fisher's exact test was used to determine any significant differences between categorical variables among the obese and nonobese groups in the $\mathrm{D}+0$ and $\mathrm{D}+\mathrm{F}$ groups. Statistical analysis was performed using IBM SPSS software version 21.0 , with significance set at the $\mathrm{p}<0.05$ level.

\section{Results}

A total of 2447 patients with LSS were identified from the QOD (Table 1). Nonobese patients accounted for $52 \%$ of the cohort, with 947 patients in the D+0 group and 319 in the $\mathrm{D}+\mathrm{F}$ group. The remaining $48 \%$ represented the obese cohort with 844 and 337 patients in the D+0 and $\mathrm{D}+\mathrm{F}$ groups, respectively.

There were no significant differences in ODI $(\mathrm{p}=$ $0.099)$, back pain $(\mathrm{p}=0.041)$, or leg pain $(\mathrm{p}=0.153)$ improvement at 12 months when comparing decompression to decompression plus fusion in either the obese or nonobese cohorts. Blood loss and operative time were lowest in the nonobese D+0 cohort (means $87.15 \mathrm{ml}$ and 95.39 minutes, $\mathrm{p}<0.000$ ). Fewer surgical levels were involved in $\mathrm{D}+0$ cases compared with $\mathrm{D}+\mathrm{F}$ cases regardless of $\mathrm{BMI}$ category $(\mathrm{p}<0.000)$. The number of surgical levels in the $\mathrm{D}+0$ and $\mathrm{D}+\mathrm{F}$ cohorts were similar regardless of BMI category. Obese patients in the $\mathrm{D}+\mathrm{F}$ group had the longest hospital stay among the 4 groups (mean 4.1 days, $\mathrm{p}<$ $0.000)$. Thirty-day readmission rates were not significantly different between obese and nonobese patients.

These findings were similar when the obese patients were further subcategorized into obese (BMI 30 to $<40$ $\mathrm{kg} / \mathrm{m}^{2}$ ) and morbidly obese (BMI $\geq 40 \mathrm{~kg} / \mathrm{m}^{2}$; Table 2).

\section{Discussion}

In the current study we compared the relative difference in performing decompression plus fusion versus decompression alone for LSS among obese and nonobese patients. The results showed no significant difference in PROs between these 2 groups when comparing decompression alone to decompression plus fusion, except that the degree of back pain relief at 1 year after surgery was higher in nonobese patients. Fusion procedures were equally effective at providing significant pain relief in both obese and nonobese patients, and such relief with respect to PROs was not significantly different from those following decompression alone.

These findings are consistent with those in a meta-analysis comparing operative outcomes (clinical and complication rates) following lumbar spine fusion, which showed significant improvement in both obese and nonobese groups; authors of that analysis concluded that obesity is not a contraindication to lumbar spinal fusion despite a 
TABLE 1. Summary of demographic and surgical data and PROs among the 4 study cohorts

\begin{tabular}{|c|c|c|c|c|c|}
\hline \multirow[b]{2}{*}{ Parameter } & \multicolumn{2}{|c|}{ Nonobese } & \multicolumn{2}{|c|}{ Obese } & \multirow[b]{2}{*}{$\begin{array}{c}p \\
\text { Value }\end{array}$} \\
\hline & $\begin{array}{l}\text { No } \\
\text { Fusion }\end{array}$ & Fusion & $\begin{array}{l}\text { No } \\
\text { Fusion }\end{array}$ & Fusion & \\
\hline No. of patients & 947 & 319 & 844 & 337 & \\
\hline Age in yrs & 68.10 & 64.26 & 63.58 & 61.51 & $<0.000$ \\
\hline $\mathrm{BMI}$ in $\mathrm{kg} / \mathrm{m}^{2}$ & 26.03 & 25.53 & 35.66 & 36.20 & $<0.000$ \\
\hline \multicolumn{6}{|l|}{ Back pain score } \\
\hline Preop & 6.17 & 6.72 & 6.39 & 7.21 & $<0.000$ \\
\hline 12-mo change & 3.34 & 3.62 & 3.03 & 3.19 & 0.041 \\
\hline \multicolumn{6}{|l|}{ Leg pain score } \\
\hline Preop & 6.70 & 6.60 & 6.73 & 6.80 & 0.814 \\
\hline 12-mo change & 4.19 & 4.16 & 3.82 & 3.98 & 0.153 \\
\hline \multicolumn{6}{|l|}{ ODI score } \\
\hline Preop & 43.70 & 48.21 & 46.91 & 51.57 & $<0.000$ \\
\hline 12-mo change & 22.92 & 24.00 & 21.25 & 21.54 & 0.099 \\
\hline No. of surgical levels & 2.18 & 1.60 & 2.25 & 1.53 & $<0.000$ \\
\hline $\begin{array}{l}\text { Estimated blood loss } \\
\text { in } \mathrm{ml}\end{array}$ & 87.15 & 281.55 & 130.87 & 340.55 & $<0.000$ \\
\hline Op time in mins & 95.39 & 179.85 & 102.77 & 186.49 & $<0.000$ \\
\hline In-hospital stay in days & 1.77 & 3.26 & 1.88 & 4.10 & $<0.000$ \\
\hline 30-day readmission & 24 & 6 & 26 & 8 & 0.685 \\
\hline
\end{tabular}

Values are means, unless otherwise indicated.

higher complication rate. ${ }^{14}$ Likewise, Djurasovic et al. performed a retrospective review and observed no significant differences in back pain, leg pain, SF-36 physical component, or ODI improvement between obese and nonobese patients undergoing lumbar spinal fusion. ${ }^{5}$

Studies have shown that obese patients, as compared with their nonobese counterparts, can expect to get significant relief from their LSS symptoms following decompression alone, although to a lesser degree. ${ }^{4,9}$ Similar findings with respect to back pain following decompression alone were seen in the current study. Although obese patients had significant improvement in back pain compared with preoperative pain levels, the 2-year postoperative numeric rating scale (NRS) back pain scores were worse than those seen in the nonobese cohort. The accepted treatment standard for degenerative LSS that has failed conservative treatment has been either decompression alone or decompression with fusion. The latter is predicated on signs of instability (spondylolisthesis), scoliosis, or patho-anatomy requiring wider decompression that would iatrogenically destabilize the spine.

The aging population and the proportion of obese adults in the US have been looming concerns for health care providers. Spine and arthroplasty surgeons will be faced with difficult decisions that are unique to the surgical treatment of obese patients. Given the higher complication rates reported among obese patients, ${ }^{21,29}$ surgeons may be inclined to perform less surgery-a nonfusion procedure in the context of LSS despite patho-anatomy and symptomatology similar to those in their nonobese coun-
TABLE 2. Summary of demographic and surgical data and PROs within the obese cohort stratified into obese and morbidly obese

\begin{tabular}{|c|c|c|c|c|c|}
\hline \multirow[b]{2}{*}{ Parameter } & \multicolumn{2}{|c|}{ Obese } & \multicolumn{2}{|c|}{ Morbidly Obese } & \multirow[b]{2}{*}{$\begin{array}{c}p \\
\text { Value }\end{array}$} \\
\hline & $\begin{array}{l}\text { No } \\
\text { Fusion }\end{array}$ & Fusion & $\begin{array}{l}\text { No } \\
\text { Fusion }\end{array}$ & Fusion & \\
\hline No. of patients & 717 & 272 & 127 & 65 & \\
\hline Age in yrs & 64.30 & 62.11 & 59.51 & 58.99 & $<0.000$ \\
\hline $\mathrm{BMl}$ in $\mathrm{kg} / \mathrm{m}^{2}$ & 33.99 & 34.19 & 45.20 & 44.60 & $<0.000$ \\
\hline \multicolumn{6}{|l|}{ Back pain score } \\
\hline Preop & 6.35 & 7.22 & 6.67 & 7.15 & $<0.000$ \\
\hline 12-mo change & 3.00 & 3.21 & 3.17 & 3.12 & 0.832 \\
\hline \multicolumn{6}{|l|}{ Leg pain score } \\
\hline Preop & 6.69 & 6.75 & 6.92 & 6.98 & 0.726 \\
\hline 12-mo change & 3.79 & 4.00 & 3.98 & 3.91 & 0.841 \\
\hline \multicolumn{6}{|l|}{ ODI score } \\
\hline Preop & 46.02 & 51.28 & 51.95 & 52.78 & $<0.000$ \\
\hline 12-mo change & 20.81 & 21.88 & 23.80 & 20.10 & 0.384 \\
\hline No. of surgical levels & 2.23 & 1.57 & 2.33 & 1.37 & $<0.000$ \\
\hline $\begin{array}{l}\text { Estimated blood loss } \\
\text { in } \mathrm{ml}\end{array}$ & 122.78 & 333.84 & 175.43 & 367.38 & $<0.000$ \\
\hline Op time in mins & 101.38 & 188.92 & 110.64 & 176.34 & $<0.000$ \\
\hline $\begin{array}{l}\text { In-hospital stay in } \\
\text { days }\end{array}$ & 1.80 & 4.20 & 2.36 & 3.69 & $<0.000$ \\
\hline 30-day readmission & 17 & 6 & 9 & 2 & 0.025 \\
\hline
\end{tabular}

Values are means, unless otherwise indicated.

terparts. Although intuitive, this philosophy has not been clearly demonstrated.

With regard to the presumed higher complication rate among obese patients, a few authors have not found any differences in either minor or major complications rates between obese and nonobese patients undergoing treatment for thoracolumbar spondylosis. ${ }^{32}$ In the current study, obese patients had a significantly longer hospital stay when fusion was performed, and blood loss was also significantly higher in obese patients regardless of whether fusion had been performed. These results are in accordance with those of Vaidya et al., ${ }^{29}$ who also demonstrated increased blood loss in obese patients following lumbar spine fusion despite significant clinical improvement. Interestingly, surgical duration was not significantly longer in obese patients when decompression and fusion were performed, but it was significantly longer in obese patients with decompression alone. When fusion was performed, the in-hospital stay was significantly longer in obese patients.

Several studies have also described a prolonged surgical duration and increased blood loss to be associated with a higher BMI., ${ }^{1,14,29}$ These findings may be attributable to patient positioning, soft-tissue dissection, and inefficient or absent specialized equipment to enable expedient surgical intervention. With respect to hospital stay, it is plausible that the higher prevalence of comorbid conditions seen in the obese group-for example, obstructive airway disease, hypertension, diabetes mellitus, and coronary artery disease-may complicate recovery and consequentially extend the hospital stay. 
Of all the complications associated with obesity, surgical site infection (SSI) has been the one complication fraught with controversy. Numerous studies have described a strong association between BMI and SSI. ${ }^{1,13,20,27}$ Interestingly, a handful of others have equally disagreed with this association. ${ }^{15,22,30,32}$ Buerba et al. ${ }^{3}$ suggested that a BMI threshold $\geq 40 \mathrm{~kg} / \mathrm{m}^{2}$ may be more of a risk factor for SSI than all BMIs $>30 \mathrm{~kg} / \mathrm{m}^{2}$. Overall, serum glucose levels or diabetes may be an even stronger risk factor for SSI than one's BMI, especially since this metric can be influenced by muscle mass or muscular body habitus and is not necessarily a surrogate of poor health.

Additionally, the controversies seen with perioperative complications between obese and nonobese patients may in part lie with nonstandardized definitions of complications. ${ }^{11,18}$ In terms of resource utilization, BMI has been shown to be an independent risk factor for increased hospital cost. ${ }^{23,24}$ This may be in part related to the extended hospital stay seen in obese patients, prolonged operating room time, and increased blood loss requiring transfusion.

Limitations to this study include those inherent with any large registry, national database, or multicenter database. The infrastructure requirements mandate a compromise between broad data collection and granular research. Thus, radiographic information as well as patient-specific variables and other clinical domains (for example, incidence of infection, fusion assessment postoperatively, and continued use of analgesic or narcotic medication) that may influence outcomes are not readily available. Documentation of diagnoses and procedures is subject to clerical or administrative human error. More long-term data are not available, and outcomes over an extended period ( $>5$ years) may differ from immediate or short-term outcomes.

\section{Conclusions}

The current data suggest that obese patients can expect to have significant clinical improvement following either decompression alone or decompression plus fusion procedures for LSS. In comparing clinical improvements between obese and nonobese patients, equivalent clinical outcomes were seen in the majority of cases (ODI, back pain, and leg pain scores). However, when decompression alone was performed, nonobese patients had significantly more back pain relief than obese patients. Obese patients should be counseled on their higher risk of perioperative complications regardless of fusion surgeries.

\section{References}

1. Abdallah DY, Jadaan MM, McCabe JP: Body mass index and risk of surgical site infection following spine surgery: a meta-analysis. Eur Spine J 22:2800-2809, 2013

2. Asher AL, Speroff T, Dittus RS, Parker SL, Davies JM, Selden N, et al: The National Neurosurgery Quality and Outcomes Database ( $\left.{ }^{2} \mathrm{QOD}\right)$ : a collaborative North American outcomes registry to advance value-based spine care. Spine (Phila Pa 1976) 39 (22 Suppl 1):S106-S116, 2014

3. Buerba RA, Fu MC, Gruskay JA, Long WD III, Grauer JN: Obese Class III patients at significantly greater risk of multiple complications after lumbar surgery: an analysis of 10,387 patients in the ACS NSQIP database. Spine J 14:2008-2018, 2014
4. Burgstaller JM, Held U, Brunner F, Porchet F, Farshad M, Steurer J, et al: The impact of obesity on the outcome of decompression surgery in degenerative lumbar spinal canal stenosis: analysis of the Lumbar Spinal Outcome Study (LSOS): A Swiss prospective multicenter cohort study. Spine (Phila Pa 1976) 41:82-89, 2016

5. Djurasovic M, Bratcher KR, Glassman SD, Dimar JR, Carreon LY: The effect of obesity on clinical outcomes after lumbar fusion. Spine (Phila Pa 1976) 33:1789-1792, 2008

6. EuroQol Group: EuroQol-a new facility for the measurement of health-related quality of life. Health Policy 16:199-208, 1999

7. Fairbank JC, Couper J, Davies JB, O’Brien JP: The Oswestry low back pain disability questionnaire. Physiotherapy 66:271-273, 1980

8. Fairbank JC, Pynsent PB: The Oswestry Disability Index. Spine (Phila Pa 1976) 25:2940-2952, 2000

9. Giannadakis C, Nerland US, Solheim O, Jakola AS, Gulati M, Weber C, et al: Does obesity affect outcomes after decompressive surgery for lumbar spinal stenosis? A multicenter, observational, registry-based study. World Neurosurg 84:1227-1234, 2015

10. Jiang J, Teng Y, Fan Z, Khan S, Xia Y: Does obesity affect the surgical outcome and complication rates of spinal surgery? A meta-analysis. Clin Orthop Relat Res 472:968975, 2014

11. Lebude B, Yadla S, Albert T, Anderson DG, Harrop JS, Hilibrand A, et al: Defining "complications" in spine surgery: neurosurgery and orthopedic spine surgeons' survey. J Spinal Disord Tech 23:493-500, 2010

12. Licht H, Murray M, Vassaur J, Jupiter DC, Regner JL, Chaput CD: The relationship of obesity to increasing healthcare burden in the setting of orthopaedic polytrauma. J Bone Joint Surg Am 97:e73, 2015

13. Lieber B, Han B, Strom RG, Mullin J, Frempong-Boadu AK, Agarwal N, et al: Preoperative predictors of spinal infection within the National Surgical Quality Inpatient Database. World Neurosurg 89:517-524, 2015

14. Lingutla KK, Pollock R, Benomran E, Purushothaman B, Kasis A, Bhatia CK, et al: Outcome of lumbar spinal fusion surgery in obese patients: a systematic review and metaanalysis. Bone Joint J 97-B:1395-1404, 2015

15. Lucas F, Emery E, Dudoit T, Berger L: Influence of obesity on access-related complications during anterior lumbar spine interbody fusion. World Neurosurg 92:229-233, 2016

16. McCaffery M, Beebe A: Pain: Clinical Manual for Nursing Practice. Baltimore: Mosby, 1993

17. McGirt MJ, Speroff T, Dittus RS, Harrell FE Jr, Asher AL: The National Neurosurgery Quality and Outcomes Database $\left(\mathrm{N}^{2} \mathrm{QOD}\right)$ : general overview and pilot-year project description. Neurosurg Focus 34(1):E6, 2013

18. Nota SP, Braun Y, Ring D, Schwab JH: Incidence of surgical site infection after spine surgery: what is the impact of the definition of infection? Clin Orthop Relat Res 473:1612 1619,2015

19. Ogden CL, Carroll MD, Kit BK, Flegal KM: Prevalence of childhood and adult obesity in the United States, 2011-2012. JAMA 311:806-814, 2014

20. Olsen MA, Nepple JJ, Riew KD, Lenke LG, Bridwell KH, Mayfield J, et al: Risk factors for surgical site infection following orthopaedic spinal operations. J Bone Joint Surg Am 90:62-69, 2008

21. Patel N, Bagan B, Vadera S, Maltenfort MG, Deutsch H, Vaccaro AR, et al: Obesity and spine surgery: relation to perioperative complications. J Neurosurg Spine 6:291-297, 2007

22. Peng CW, Bendo JA, Goldstein JA, Nalbandian MM: Perioperative outcomes of anterior lumbar surgery in obese versus non-obese patients. Spine J 9:715-720, 2009 
23. Planchard RF, Higgins DM, Mallory GW, Puffer RC, Jacob JT, Curry TB, et al: The impact of obesity on perioperative resource utilization after elective spine surgery for degenerative disease. Global Spine J 5:287-293, 2015

24. Puffer RC, Planchard R, Mallory GW, Clarke MJ: Patientspecific factors affecting hospital costs in lumbar spine surgery. J Neurosurg Spine 24:1-6, 2016

25. Rihn JA, Radcliff K, Hilibrand AS, Anderson DT, Zhao W, Lurie J, et al: Does obesity affect outcomes of treatment for lumbar stenosis and degenerative spondylolisthesis? Analysis of the Spine Patient Outcomes Research Trial (SPORT). Spine (Phila Pa 1976) 37:1933-1946, 2012

26. Sabharwal S, Root MZ: Impact of obesity on orthopaedics. J Bone Joint Surg Am 94:1045-1052, 2012

27. Sebastian A, Huddleston P III, Kakar S, Habermann E, Wagie A, Nassr A: Risk factors for surgical site infection after posterior cervical spine surgery: an analysis of 5441 patients from the ACS-NSQIP 2005-2012. Spine J 16:S1529-S9430, 2015

28. Soroceanu A, Burton DC, Diebo BG, Smith JS, Hostin R, Shaffrey CI, et al: Impact of obesity on complications, infection, and patient-reported outcomes in adult spinal deformity surgery. J Neurosurg Spine 31:1-9, 2015

29. Vaidya R, Carp J, Bartol S, Ouellette N, Lee S, Sethi A: Lumbar spine fusion in obese and morbidly obese patients. Spine (Phila Pa 1976) 34:495-500, 2009

30. Watanabe M, Sakai D, Matsuyama D, Yamamoto Y, Sato M, Mochida J: Risk factors for surgical site infection following spine surgery: efficacy of intraoperative saline irrigation. J Neurosurg Spine 12:540-546, 2010

31. Wills M: Orthopedic complications of childhood obesity. Pediatr Phys Ther 16:230-235, 2004

32. Yadla S, Malone J, Campbell PG, Maltenfort MG, Harrop JS, Sharan AD, et al: Obesity and spine surgery: reassessment based on a prospective evaluation of perioperative complications in elective degenerative thoracolumbar procedures. Spine J 10:581-587, 2010

\section{Disclosures}

Dr. Carreon is a consultant for AOSpine and Washington University School of Medicine and has received travel funds from the University of Southern Denmark. Dr. Glassman holds a patent with and is a consultant for Medtronic. Dr. Mummaneni is a consultant for DePuy Spine; holds stock in Spinicity/ISD; receives royalties from DePuy Spine, Springer Publishing, Thieme Publishing, and Taylor \& Francis Publishing; and has received honoraria from AOSpine. Dr. Shaffrey is a consultant for Medtronic, NuVasive, Zimmer-Biomet, K2M, and Stryker; holds stock in NuVasive; holds patents with Medtronic, NuVasive, and Zimmer-Biomet; and has received support from DePuy Synthes for non-study-related clinical or research effort.

\section{Author Contributions}

Conception and design: Glassman. Acquisition of data: Carreon, Glassman, Asher, Shaffrey, Mummaneni. Analysis and interpretation of data: Carreon, Onyekwelu, Glassman. Drafting the article: Onyekwelu. Critically revising the article: Carreon, Onyekwelu, Glassman, Shaffrey, Mummaneni. Reviewed submitted version of manuscript: Carreon, Asher, Shaffrey, Mummaneni. Approved the final version of the manuscript on behalf of all authors: Carreon. Statistical analysis: Carreon. Administrative/technical/material support: Asher, Shaffrey.

\section{Correspondence}

Leah Y. Carreon, Norton Leatherman Spine Center, 210 East Gray St., Ste.900, Louisville, KY 40202. email: leah.carreon@ nortonhealthcare.org. 